\title{
Understanding the global refugee crisis: managerial consequences and policy implications
}

Article

Accepted Version

Chun Guo, G., Al Ariss, A. and Brewster, C. (2020) Understanding the global refugee crisis: managerial consequences and policy implications. Academy of Management Perspectives, 34 (4). pp. 531-545. ISSN 15589080 doi: https://doi.org/10.5465/amp.2019.0013 Available at https://centaur.reading.ac.uk/89978/

It is advisable to refer to the publisher's version if you intend to cite from the work. See Guidance on citing.

To link to this article DOI: http://dx.doi.org/10.5465/amp.2019.0013

Publisher: Academy of Management

All outputs in CentAUR are protected by Intellectual Property Rights law, including copyright law. Copyright and IPR is retained by the creators or other copyright holders. Terms and conditions for use of this material are defined in the End User Agreement.

www.reading.ac.uk/centaur 
Central Archive at the University of Reading

Reading's research outputs online 


\title{
UNDERSTANDING THE GLOBAL REFUGEE CRISIS: \\ MANAGERIAL CONSEQUENCES AND POLICY IMPLICATIONS
}

\author{
Grace Chun Guo* \\ Jack Welch College of Business \& Technology \\ Sacred Heart University \\ 5151 Park Ave. Fairfield, CT, USA \\ chun-guog@sacredheart.edu
}

\author{
Akram Al Ariss \\ TBS Business School \\ 1 Place Alphonse Jourdain - CS 66810 \\ 31068 TOULOUSE Cedex 7, France \\ a.alariss@tbs-education.fr
}

Chris Brewster

Henley Business School,

University of Reading,

Whiteknights, Reading, RG6 6UD, UK

c.j.brewster@henley.ac.uk

*Corresponding author 


\title{
UNDERSTANDING THE GLOBAL REFUGEE CRISIS: MANAGERIAL CONSEQUENCES AND POLICY IMPLICATIONS
}

\begin{abstract}
The number of refugees is predicted to increase continually this century. We tackle the topic of the global refugee crisis and, in particular, its business and management implications. We investigate the dynamics of refugee integration and settlement processes, and present evidence for the specific challenges associated with the refugee crisis. Drawing on the organizational justice and inclusion literatures, we present the benefits of using organizational justice theory as a template for understanding refugee inclusion and for developing organizational practices and policies that support refugee inclusion. Supporting the UN's call for more company participation in achieving Sustainable Development Goals, we argue for more active involvement of host country organizations as part of the solution to this global crisis. We also call for greater attention from business and management scholars to issues related to forced migration and refugee inclusion in the workplace. We discuss implications for theory, business practices, and public policies.
\end{abstract}

Keywords: Forced Migration, Inclusion, Organizational Justice, Refugee Crisis, Refugee Integration, Refugee Settlement 
The number of international migrants worldwide continues to grow rapidly, reaching well over 250 million by 2017, a 49\% increase since 2000 (United Nation, 2017). Among these international migrants, about $10 \%$ are 'forced' according to the International Migration Report (2017): They are what is generally referred to as "refugee and other forcibly displaced populations, which may be primarily due to war and conflict, but also can be due to political, religious, and other persecution, national or man-made disasters; development-induced displacement; smuggling and human trafficking; and environmental displacement" (Reed, 2018, p. 2). Forced migration is one of the most pressing global issues of our time (Salehyan, 2019). The United Nations refugee convention (1951) notes that asylum seekers and refugees are the same people at different stages of a process: asylum seekers are people who have had to leave their country and are seeking protection from persecution, refugees are similar people who have achieved such protection. For simplicity in this paper we shall refer to both categories as refugees. The number of refugees is predicted to increase continually throughout this century. These refugees face tensions with host community populations, struggles to secure first needs like security and food, and they face under-employment, exploitation, harassment, exclusion, and subordination (Campion, 2018; Knappert, Kornau, \& Figengul, 2018; Orhan 2014).

Supporting the UN's call for more active company participation in achieving the SDGs (United Nations, 2015), this paper argues that host country organizations, through their managerial strategies, policies and practices, have a role to play in facilitating the integration of refugees. Researchers studying refugees and their integration (Campion, 2018; Phillimore \& Goodson, 2006) suggest that employment is the single most important factor in achieving successful integration in the host society. However, businesses are not well prepared to manage issues associated with refugees (Naccache \& Al Ariss, 2017). The challenges facing refugees and 
their host countries have been the subject of many different disciplines (politics, sociology, economics, economic geography, etc.), but the management literature has mainly examined economic migrants, those who voluntarily leave their home countries to pursue better career opportunities (Cerdin, Abdeljalil-Diné, \& Brewster, 2014). Much of the literature examines their international career moves and associated push and pull factors (Al Ariss, Koall, Özbilgin, \& Suutari, 2012; Carr, Inkson, \& Thorn, 2005; Thomas, Lazarova, \& Inkson, 2005), but little attention has been directed to issues related to forced migration, the refugee crisis, and the implications for management theory and practice. Therefore, building on the organizational justice and inclusion literatures, this paper expands on organizational practices and policies that support refugee inclusion.

The current refugee crisis has been commonly cited as being the greatest since the end of World War II and the formation of the international refugee regime (Braithwaite, Salehyan, \& Savun, 2019). In recent years Syria and Afghanistan are the two countries from which most people have fled (UNHCR, 2016). By 2018, an estimated 6.5 million people were internally displaced within Syria, and 5.6 million fled seeking temporary protection in neighboring and European countries (UNHCR, 2018a). This is not just a European problem: Pakistan, for example, has an estimated 2.3 million refugees from Afghanistan, with nearly half of them being undocumented (Marfleet \& Blustein, 2011; UNHCR, 2016).

In many countries, public attitudes towards refugees show majorities in favor of rights for refugees (exceptions include France, Hungary and Japan), but with skepticism about whether refugees genuinely have been forced out of their home countries and doubts about whether they can be integrated into their new society (IPSOS, 2019). Majorities in India, Turkey, Sweden and Serbia believe that their countries should close their borders to refugees (ibid.). As a result, 
politicians have played to these galleries and much needed social and political support for these people has been far from adequate and universal. For example, in the United States, the Trump administration drastically reduced the refugee resettlement numbers from 110,000 in 2016 to 18,000 in 2019 and imposed travel bans from several Muslim-majority nations (Shear \& KannoYongs, 2019). In Europe, between 2015 and 2019 the European Union (EU) provided over $€ 23$ billion ( $€ 25.5$ billion) to EU members states, agencies and nearby countries to enable them to manage migration better (European Commission, 2019) but this was used differently in different member states, with some using it to assist resettlement and others using it to enhance border controls. The Hungarian government of Viktor Orbán is pursuing a 'zero refugee' strategy to ensure that Hungary does not 'lose its identity', a policy that has led the United Nations High Commission for Refugees to call for the country to withdraw a package of laws (UNHCR, 2018b). Such examples could be multiplied. Despite the view of refugees as economic problems and security risks, refugees can present opportunities to host countries (Salehyan, 2019). For example, over their first 20 years in the USA, refugees aged 18-45 paid about $\$ 21,324$ more in tax than then they take home in benefits, hence a net positive fiscal impact in the long run (Evans \& Fitzgerald, 2017). They outperformed other migrants in terms of their labor market participation, income and language proficiency (Cortes, 2004).

World leaders and international communities have recognized and worked together to tackle the refugee crises, including signing the most recent New York Declaration for Refugees and Migrants on September 19, 2016. Twelve months earlier, the 193 Member States of the United Nations adopted 'Agenda 2030', which included agreement to 17 Sustainable Development Goals (SDGs). One of these goals (Goal 8) was promoting sustained, inclusive and sustainable economic growth, full and productive employment, and decent work for all. Agenda 
2030 calls for companies' participation in the implementation of the SDGs, because "business can be architects and builders of sustainable development and social inclusion, creating shared value and entering into a new era of corporate sustainability as business-as-usual" (Nelson, Jenkins, \& Gilbert, 2015, p. 1). There has been a steadily increasing pressure on businesses to not just cope with such issues, but to make a positive contribution to handling them (Wettstein, Guiliani, Santangelo, \& Stahl, 2019). By 2020, 10,000 companies had joined the UN's Global Compact with business to address this issue amongst others ("20 Years of the UN Global Compact", n.d.).

Given the acceptance of the important role of business and specifically of employment in integration, and the limited understanding of this phenomenon in the management literature, this paper explores the role of host country organizations in receiving and integrating refugees in the local workforce so that the implications for government policies and management practices can be identified. In this paper, we investigate the dynamics of, and factors contributing to, refugee inclusion as a partial solution to managing the refugee crisis. Previous studies (e.g. Hicks-Clarke \& Iles, 2000; Mor Barak \& Cherin, 1998; Kossek \& Zonia, 1993; Roberson, 2006; Roberson \& Stevens, 2006; Shore, Randel, Chung, Dean, Ehrhart, \& Singh, 2011) have shown the relevance of justice perceptions and the fairness of organizational practices in fostering diversity and inclusion while eliminating discrimination. Drawing on the organizational justice theory (e.g. Colquitt, 2001; Colquitt, Conlon, Wesson, Porter, \& Ng , 2001) as well as the inclusion literature (Shore et al., 2011), we discuss how different forms of organizational justice (Colquitt, 2001) may create a fair working environment that facilitates inclusion of refugee employees in the host country organization. In doing so, we make suggestions about how host country governments and organizations can respond to this global crisis by developing national and management 
practices that recognize and utilize the unique contributions of refugees and embrace them as valued citizens and organizational members.

The paper is organized as follows: first we establish the nature of the global refugee crisis and discuss the key challenges it creates for businesses and for refugees themselves. Second, we tackle the topic of refugee inclusion in the workplace and present the benefits of using organizational justice theory as a template for understanding and implementing refugee inclusion. Finally, building on this discussion, we examine the role that host country organizations could play in order to tackle these challenges, discussing the implications for theory, business practices and public policies.

\section{CHALLENGES OF THE REFUGEE CRISIS}

Refugees are not a homogenous group but individuals with varying degrees of education, skills and professional experiences (Campion, 2018). Unlike economic migrants, the crises that they face as a result of political or racial persecution, natural disaster or other life-threatening situations, tend to affect all members of a community more or less equally. Thus refugees include people of all levels of status and education, and from all sectors of the economy. Refugees rarely have the opportunity to assess their new country's economic situation, business structure, or regulations. History has taught us that the presence of international migrants, especially in large numbers, can be viewed as a threat and can trigger xenophobia among host country nationals (Naccache \& $\mathrm{Al}$ Ariss, 2017). It is difficult for refugees to demonstrate their professional credentials and skills, as they may not have kept relevant documents when fleeing their home country. It is unlikely that they will speak the language of the host country or have family and professional ties with people there who can provide support and guidance when they arrive. Some refugees also suffer from traumatic stress. Refugees therefore often find it difficult 
to get work. All these circumstances make refugees the most vulnerable members of the society (Campion, 2018; Gericke, Burmeister, Lowe, Deller, \& Pundt, 2018; Hakak \& Al Ariss, 2013). One result is that, for example, oftentimes former government officials and medical doctors will end up working as taxi drivers or parking attendants in their new country (Brandt, 2010).

In these circumstances, it is not surprising that refugees may take up entrepreneurial work, partly perhaps to avoid some of the problems they associate with trying to find employment. It has been argued (Buckley and Casson, 1991) that some cultures are intrinsically more entrepreneurial than others and refugees can bring those skills into a country. Immigrants generally have been found to be more likely than indigenous populations to start new ventures in the United States (Fairlie, 2008), Canada (Schuetze \& Antecol, 2006), United Kingdom (Clark \& Drinkwater, 2000) and Australia (Collins, 2003). Likewise, a report by the reveals that Immigrants and their children founded $44 \%$ of the Fortune 500 firms (New American Economy, 2018) and more than half the IT start-ups in Silicon Valley (Saxenian, 2005). We do not know what proportion of those immigrants were refugees, because they have not been studied specifically, but many of them will have been.

Most refugees will look for employment. Scholars (Campion, 2018; Eggenhofer-Rehart, Latzke, Pernkopf, Zellhofer, Mayrhofer, \& Steyrer, 2018; Gericke et al., 2018; Knappert et al., 2018) maintain that stable employment is crucial for refugees' successful resettlement, wellbeing, and integration in the host country. While the effort to provide basic services (food and shelter) generally succeeds at some level, integration of refugees into the local labor market is reported to be difficult. For example, in Austria, only $15.2 \%$ of those who received work permits between January 2015 and June 2016 were employed by December 2016 (Eggenhofer-Rehart et al., 2018). In Germany, half the refugees looking for work had failed to find a job five years after 
entering the country (Brücker, Hauptmann, \& Vallizadeh, 2015). In Sweden, employment rates remain behind locals for their whole lifetime (Lundborg, 2013). Eggenhofer-Rehart et al. (2018) found that refugees from Syria and Afghanistan were unfamiliar with the formal job application processes in Austria, because at home they relied on informal procedures and social capital. In Syria and Afghanistan, job experience can be acquired by informal apprenticeships and, in the private sector, it is uncommon for employers to formalize employment, whereas in Austria, most jobs require formal educational qualifications, are transactional, and based on merit (EggenhoferRehart et al., 2018). These concerns mean that most refugees upon arrival in the destination countries struggle with securing stable employment, feel 'trapped' in the host countries, and become victims of precarious employment practices, including short-term contracts, low pay, lack of voice, exclusion, discrimination, sexual harassment and exploitation (Kroon \& Paauwe, 2014).

For those 'lucky few' who manage to secure employment, the workplace treatment they receive is often far from fair and just. Refugees have been reported as being subject to workplace discrimination, inequality, harassment and skill degradation (Diet, Esses, Hamilton, \& Gabarrot, 2015; Knappert et al., 2018). For example, Knappert et al. (2018) found that in Turkey some employers considered unequal treatment of refugees as 'legitimate'. Refugees were hired as temporary cheap labor to perform undesirable jobs because they had to take the job as a necessity to survive; employers arbitrarily paid refugees less even though they worked the same jobs as locals; female refugees were victims of sexual harassment as they were viewed by locals as prostitutes (Knappert et al., 2018). Cultural, religious and other social differences may also make integration difficult. For example, Pajic, Ulceluse, Kismihók, \& Mol (2018) note that post-2014 refugees (following the start of the war in Syria) are likely to experience more social challenges 
due to their different cultural backgrounds than previous refugee cohorts in Europe (such as those from the Yugoslav war in the 1990s).

\section{REFUGEE RESETTLEMENT PROCESS}

Refugee integration and resettlement processes have received little attention in the business and management literature. Some recent studies provide empirical evidence of these processes, involving different 'agents', including host country governments, non-profit organizations, ethnic communities, and host-country organizations. Specifically, research showed that host country governments and non-profit organizations provided critical support and resources at the initial stage of the integration and resettlement process. Campion (2018), studying refugee resettlement processes in the EU and the USA, found that government agencies and non-profit organizations tried to place refugees in cities with available jobs and communities of the same ethnicity. These resettlement agencies assist with housing, employment service, host country language courses, and healthcare. In this process, welfare for refugees is limited - for instance, aid often ends six months after arrival in the USA (Campion, 2018). Based on a qualitative study involving interviews with Syrian refugees who secured employment in Germany, Gericke et al. (2018) found that at the early integration stage, support provided by volunteers and social workers in the form of donated goods, help with finding accommodation, and dealing with administrative and legal processes was crucial for refugees in order to navigate their new life in the host country. When preparing refugees' entry into the local labor market, volunteers, government officials, and non-government organizations (NGOs) employees also provided structured support with formal job applications, assisting with translating CVs and certificates, writing applications, dealing with complex administrative processes to verify 
refugees' qualifications, and providing language lessons, all of which increased refugees' chances of being hired (Gericke et al., 2018).

After the initial stage of settling into the host country, some refugees secured their first job or internship through their social network connections with social workers and NGO employees, who offered them direct referrals or jobs as translators or as social workers for other refugees (Gericke et al., 2018). Due to the limited welfare and resources provided by the host country government, as well as time pressure and economic need, refugees' ethnic communities, where they exist, usually play an important role in providing refugees with quick access to employment and knowledge about the culture of the host country. Gericke et al. (2018) found that horizontal bonding ties with family members and members of the local ethnic community helped refugees gain access to social activities and develop a better understanding of German culture. Campion's (2018) study showed that refugees were motivated to rely on social ties from the ethnic community for quick employment and often accepted the first employment opportunity presented. As a result, 'ethnic niche employment' is likely to occur, evidenced by the assimilation of forced migrants into the same industry in a host country. While the support from ethnically similar others helps secure safety in an uncertain environment, fulfills the need to belong, and provides quicker employment, it does not usually align with forced migrants' qualifications and does not necessarily result in high-quality employment. In fact, such support acts as barrier to higher paying jobs and reinforces gender stereotyping (Campion, 2018).

Gericke et al. (2018) also examined the role of host country organizations in facilitating refugees' integration into the workforce after they are hired, one of very few studies to do this. They found that receiving support from co-workers and supervisors and being included in social activities at work and outside of work had a significant positive impact on integrating refugees 
into the local workforce. Refugees' German co-workers and supervisors not only provided language support but also task-related support, including taking extra time to explain their tasks, providing a mentor or opportunities to get to know different employees and work processes, and assisting with administrative processes or formalities regarding their legal status or work permit. One approach to understanding refugee inclusion in the workplace involves using the lens of organizational justice and so next we consider inclusion and then organizational justice.

\section{WORKPLACE INCLUSION}

There are major advantages for firms in recruiting and including refugees. Again, most of what we know comes from studies of migrants rather than refugees per se, but it is likely that some learning at least may read across. The long-held and widely accepted notion that national circumstances and contexts create strong tendencies in how companies are created and managed (Porter, 1990; Hofstede, 1980) is challenged by multiple theories and research studies reporting that perceptions, attitudes, and behaviors can spillover from one context into another (Alderfer \& Smith, 1982; Ilies, Wilson, \& Wagner, 2009; Mennino, Rubin, \& Brayfield, 2005; Pateman, 1970). Refugees are not only grateful for work but bring to work a different perspective than indigenous employees.

Researchers have explored ways to create work environments where diverse individuals feel included (Mor Barak, 2000; Mor Barak \& Cherin, 1998; Thomas \& Ely, 1996). Early work on workplace inclusion focused on the organizational processes that could lead to employees' perception of inclusion versus exclusion (e.g. Mor Barak \& Cherin, 1998; Mor Barak, 2000; Pelled, Ledford, \& Mohrman, 2009). It is well recognized that diversity can create a competitive advantage and bring benefits for the organization (Cox \& Blake, 1991; Robinson \& Dechant, 1997), but it also brings problems. Mor Barak (2000) argues that the problems arising from 
diversity are caused not by the changes in the workforce composition itself but by the inability of companies to truly integrate and leverage a heterogenous workforce at all levels: whilst affirmative action programs may help women, older employees, and members of ethnic and racial minorities get on board, the visible differentiation of these members keeps them from being in the circle of influence and from fully contributing and benefiting from their involvement (Mor Barak, 2000).

Despite these pioneer studies, inclusion literature is still in its infancy (Shore et al., 2011). Based on Brewer's optimal distinctiveness theory (ODT), Shore et al. (2011) developed a twoby-two framework that they used as a lens for reviewing the literature. Based on different combinations of high versus low value in uniqueness and belongingness, Shore et al. (2011) identified four different approaches: exclusion, assimilation, differentiation and inclusion. Exclusion refers to the situation in which the employee is not treated as an organizational insider with unique values, hence a low-belongingness/ low-uniqueness combination. Assimilation reflects situations in which an employee is treated as an insider when he or she conforms to the dominant norms of the culture, hence a high belongingness/ low-uniqueness combination. Differentiation refers to situations in which individuals have high needs for uniqueness (e.g. employees who have unique and rare capabilities) and but are not considered or treated as organizational insiders, hence a high-uniqueness/ low-belongingness combination. Lastly, inclusion, a combination of high value in uniqueness and high belongingness, refers to "the degree to which an employee perceives that he or she is an esteemed member of the work group through experiencing treatment that satisfies his or her needs for both belongingness and uniqueness" (Shore et al., 2011, p.1256). Shore et al. (2011, p. 1286) suggest that the theme of belongingness may be demonstrated by keywords and phrases such as "accepted" and "insider", 
whereas the theme of uniqueness may include keywords and phrases such as "contribute fully", "individual talents", and "to have their voices heard and appreciated".

The dual-focus on both value in uniqueness and belongingness sets Shore et al.'s (2011) construction of inclusion apart from other diversity theoretical perspectives, which most commonly adopt relational demography and similarity-attract paradigms and emphasize group belongingness. Shore et al. (2011) argue that belongingness should be accompanied by being valued for uniqueness to promote employees' perception of inclusion in work groups. They maintain that dissimilarity from other groups, or being unique, may not necessarily result in dislike and inherently negative effects—-the assumption of "symmetrical effects" (p.1272). In other words, when distinct groups work interdependently, members retain positive views of their own group and can also perceive outgroups as having both unique and positive attributes. For example, being a token is not necessarily a negative experience; when tokens are valued for their uniqueness, they can still feel a sense of belongingness (Shore et al., 2011).

Refugee employees are most commonly treated as outsiders and are excluded from being part of the circle of influence or decision making, illustrating the case of exclusion in Shore et al.'s (2011) typology. In cases where refugees had a positive experience in the resettlement and integration process, the reported evidence (e.g. Gericke et al., 2018) shows that there is a high need for them to adopt the assimilation strategy so that they can acquire host country language skills, knowledge of social norms and employment practices, as well as local professional certification or qualifications in order to secure employment. The pressure to secure quick jobs because of the fear of losing temporary refugee aid and the need for belongingness or fit-in after being resettled in the host country may lead to short-term success in refugees' objective resettlement, defined by Campion (2018) as reaching acceptable job status, pay, and opportunity 
for host country growth. However, with the high level of pressure of assimilation that is common in the job search process, refugees' uniqueness, associated with their ethnic minority background and refugee status, is likely not to be fully valued by organizations, preventing them from being fully included in the host organization, fully involved or able to contribute as an insider. This may result in long-term failure in refugees' subjective resettlement, which according to Campion (2018), is based on an individual's strength of social ties, work/ life satisfaction, and mental and physical health.

Drawing on rejection sensitivity theory, Newman, Nielsen, Symth, Hirst and Kennedy (2018) argue that refugees, as both minority group members and refugees, are more likely to face discrimination and exclusion, and hence they are likely to be more sensitive to workplace treatment. They will monitor organization policies and practices to evaluate whether their ethnic background is respected within the workplace (Newman et al., 2018). Newman et al. (2018) found evidence that the effects of diversity climates (i.e. the extent to which organization values the contribution of under-represented employees) that fostered inclusion were more pronounced for refugees coming from more collectivistic cultures such as those in the Middle East and Central Asia, who had higher levels of identity with their ethnic group. Newman et al. (2018) also found that a diversity climate was positively associated with refugees' organizational commitment through its effect on their psychological capital, an individual's positive psychological state of development including hope, resilience, optimism and self-efficacy.

In short, the inclusion literature and the recent studies done on refugee integration and workplace treatment inform us that some host country organizations have taken initiatives in including refugees in the workplace through creating a diversity climate and providing support to facilitate better transition to new job positions. However, improvement is still needed in areas 
such as establishing organizational processes and practices that not only minimize discrimination toward refugees and promotes their sense of belongingness but also ones that respect their ethnic identity, recognize their unique value and contributions to the organization, and promote their inclusion in the host country organization. As an initial effort, in the next section we discuss how organizational justice theory may provide potential solutions to achieve this goal.

\section{ORGANIZATIONAL JUSTICE THEORY}

Previous studies in diversity, inclusion, and discrimination (e.g. Hicks-Clarke \& Iles, 2000; Mor Barak \& Cherin, 1998; Kossek \& Zonia, 1993; Roberson, 2006; Roberson \& Stevens, 2006; Shore et al., 2011) have shown the relevance and importance of justice perceptions and the fairness of organizational practices. Drawing on organizational justice theory (e.g. Colquitt et al., 2001) and the inclusion and integration literature (Shore et al., 2011), we discuss the importance of different types of organizational justice (Colquitt, 2001) in creating a fair working environment that allows for better refugee inclusion in the workforce.

Organizational justice connects access to the workforce and fair treatment at work (Cropanzano, Bowen, \& Gilliland, 2007; Hassan \& Hashim, 2011; Rupp, Shapiro, Folger, Skarlicki, \& Shao, 2017). Justice concerns are found to be especially salient among members of diverse communities (Roberson \& Stevens, 2006; Shore et al., 2011), who are usually threatened based on their sub-group related identities and are more likely subject to workplace discrimination (Buengeler \& den Hartog, 2015). Shore et al. (2011) argue that "justice pertaining to fair treatment of diverse employees are particularly relevant to inclusion" (p. 1276) and that "a climate of inclusion is one in which policies, procedures, and actions of organizational agents are consistent with fair treatment of all social groups, with particular attention to groups that have had fewer opportunities historically and that are stigmatized in the societies in which they live" 
(p. 1277). Farndale, Biron, Briscoe and Raghuram (2015) maintain that perceptions of fairness can enhance inclusion by creating an environment in which all employees, regardless of their gender, age, or nationality, can feel that they are treated equally. Nishii (2013) found evidence that equitable employment practices are the foundation for building a climate of inclusion: These equitable employment practices include fair promotion processes, fair performance review processes, equal pay for equal work, and availability of safe ways for employees to voice their grievances.

Organizational justice describes 'individuals' and the group's perception of the fairness of treatment (including, but not limited to, allocations) received from an organization and their behavior reaction to such perceptions" (James, 1993, p. 21). The management literature has identified four types of organizational justice in the workplace - procedural justice, distributive justice, informational justice and interpersonal justice (Colquitt, 2001), though, arguably, informational justice is an aspect of procedural justice and interpersonal justice is an aspect of distributive justice (Greenberg, 1993).

Procedural justice refers to the perceived fairness of decision-making procedures which can be attained via structural means (Greenberg, 1993). Dimensions of procedural justices include Thibaut and Walker's (1975) process control effect (e.g. the ability to influence the decision making process that leads to certain outcomes), Folger and Greenberg's (1985) voice effect (e.g. the ability to express one's views and points in the decision making process), and Leventhal's (1980) decision-making rules (consistency, bias-suppression, accuracy, correctability, representativeness and ethicality). There are two models of procedural justice. The control model, comprising 'process control effects' and 'voice effects' is considered instrumental in achieving fair economic and material outcomes (Blader \& Tyler, 2005). An 
alternative approach, the relational model of procedural justice, suggests that non-instrumental and relational criteria will affect procedural justice judgements and that procedural justice is closely associated with one's group-identity. According to this model, employees make evaluations about their identities as members of their organization - pride (perceptions of the status of the group), respect (perceptions of one's status of standing within the group), and identification (the extent to which employees define themselves as members of the group) based on the procedural justice they experience (Blader \& Tyler, 2005).

Distributive justice refers to the perceptions of fairness in outcomes that are accomplished via structural means (Greenberg, 1993). According to Colquitt (2001), one measure of distributive justice is when the allocation norm is consistent with stated goals. There are three main allocation norms: equity, equality and need. The equity norm refers to allocation in proportion to one's contribution, the equality norm is about similar reward allocation, which may be related to contribution, and the need norm suggests that allocations are based on one's personal requirements. Cropanzano et al. (2007) maintain that organizations may apply one or a combination of these norms depending on strategic goals.

Informational justice refers to the perceptions of fairness in providing knowledge about, or openly sharing information of, procedures (Greenberg, 1993) and distribution of outcomes. Drawing on prior research (e.g. Bies \& Moag, 1986; Greenberg, 1993), Colquitt (2001) identified three dimensions of informational justice: truthfulness, justification, and adequacy of explanations. Truthfulness requires an authority figure to be candid and not engage in deception; justification is about explaining the basis for decision; and adequacy of explanations suggests that explanations are reasonable, timely and specific (Colquitt, 2001). 
Interpersonal justice, finally, refers to perceived fairness in outcomes that can be achieved via social means (Greenberg, 1993). In other words, interpersonal justice is demonstrated by showing concern for individuals. Based on Bies and Moag's (1986) study, Colquitt (2001) identified two dimensions: propriety and respect. Propriety refers to refraining from improper remarks or prejudicial statements, and respect refers to being polite.

\section{IMPLICATIONS FOR REFUGEE INCLUSION IN THE WORKPLACE}

In this section, we use the two literatures on organizational justice and workplace inclusion to identify justice-based practices which will help host-country organizations address refugees' need for uniqueness and enhance their sense of belongingness.

\section{Procedural Justice}

First, we expect that the control model of procedural justice - the voice effect and the process control effect - would directly tackle the vulnerability of refugees. The most salient obstacle facing refugees is that they lack language proficiency and knowledge of the local social norms and business practices. Hence, refugees remain largely a silenced group, subject to workplace mistreatment, discrimination and exploitation. In addition, as newcomers in the host country, they may not feel comfortable speaking up. Host country organizations can implement procedures at different time points (e.g. hiring, on-site training, continuous development) to proactively reach out to refugees in recruitment, and to encourage recruited refugees to express their opinions and concerns. These procedures may be accompanied by language training programs or translation services to enable refugees to speak up with more confidence. Such practices will demonstrate host country organizations' valuing of refugees' unique ethnocultural backgrounds and professional experiences, which in turn, may enhance refugees' sense of inclusion in the workplace. In addition, we expect that the relational model will most likely 
enhance refugees' perceptions of belongingness by creating a high level of identification with the host country organization. When refugees view their host country organizations as operating and treating them in a procedurally fair manner, they are likely to infer that the organization is one they can trust and be proud of and that they are respected members of that organization. These positive evaluations, according to Tyler and Blader $(2001 ; 2003)$, in turn, will influence employees' level of identification with the organization.

In addition, Leventhal's (1980) decision-making rules - consistency, bias-suppression, accuracy, correctability, representativeness and ethicality - if implemented in personnel practices and procedures in the organization, could effectively minimize discrimination toward refugees. The consistency rule requires the organization to treat all employees, including refugees in similar situations over time consistently. Bias-suppression and accuracy point the same way with decisions taken based on accurate, objective information. The correctability rule ensures that mistreatment or wrongful decisions can be corrected and reversed. The representativeness rule allows refugees or their representatives to participate in the decision-making process so that their concerns, values and outlooks can have an impact on the allocation of benefits and on processes. Lastly, the ethicality rule requires organizational rules, processes and procedures to follow fundamental ethical rules and moral principles. These decision-making rules could ensure that refugees receive equal treatment as those received by the local employees, hence promoting their inclusion in the workplace and full participation in organizational activities as an organizational insider.

\section{Distributive Justice}

In the context of refugee inclusion, we suggest that host country organizations employ a combination of all three allocation norms to address the needs of belongingness and uniqueness 
to ensure inclusion of refugees. Specifically, the equity norm suggests that in the hiring process, due to the difficulty in assessing refugees' qualifications, host country organizations allow extra time and resources (e.g. working with the government social programs and hiring translation services), or design in-house qualification procedures to carefully and thoroughly evaluate refugees' education backgrounds, skill levels, and prior relevant experiences. Such evaluations, although time-consuming, could ensure that refugees' unique skills, experiences and crosscultural perspectives can be properly recognized and hence provide opportunities for creativity and enhancement of current organizational systems. To foster the sense of belongness, we suggest that organizations apply the need norm and allocate resources to support the on-going needs of the refugees at work such as providing continuous training programs and work-specific language courses as well as accommodations for refugee employees' religious beliefs or practices. Companies may provide on-site counseling services as some refugees suffer from traumatic stress. Host organizations may also consider flexible work schedule at least initially if refugee employees need assistance in setting up childcare arrangements. In addition, we suggest that organizations consider applying the equality rule by teaming up refugees with local employees and assigning them to work on the same task, providing the same challenges and the same basic team-based compensation and benefits. These team assignments will allow local employees to overcome potential stereotypes, get to know refugees on a personal level and learn news ways of conducting business, therefore fostering refugee inclusion in the workplace.

\section{Informational Justice}

The truthfulness rule is important in ensuring that refugees are informed about their workplace legal rights, company rules and work processes. Given the frequent lack of language proficiency and knowledge of social norms and local business practices, it is unsurprising that 
research (Gericke et al., 2018) shows that refugee employees experienced smoother transitions into new jobs when their supervisors and colleagues spent extra time and provided multiple opportunities to explain their tasks or other work-related issues. In this case, supervisors should thoroughly explain the basis for decisions (justification) and expect to provide specific explanations in multiple ways when refugee employees have difficulty in understanding or discussing work-related issues (adequacy of explanations). Such practices will demonstrate that refugees are treated as valued organizational members, hence enhancing refugees' sense of belongingness and perceived inclusion in the workplace.

\section{Interpersonal Justice}

Rules of propriety and respect should serve as the guiding principles of workplace interpersonal interactions so that refugees' cultural and ethnic identities are given due regard, and improper remarks based on false, negative cultural stereotypes are not tolerated. We believe that sensitivity should be another interpersonal justice rule in the context of refugees. This is especially the case because some refugees suffer from traumatic stress due to life-threatening situations such as civil wars, genocide and torture in their home country. As suggested by Campion (2018), psychologists who specialize in trauma could be invited to provide training for supervisors and local employees on how to interact and supervise refugee employees in a culturally appropriate way. Such practices allow host country organizations to pay special attention to designing proper accommodation due to refugee employees' traumatic experience. Last, but not least, bridging social ties, or connections that may provide access to valuable career-related information and offer social mobility, is critical for refugees to access employment information (Gericke et al., 2018). Interpersonal justice rules will likely help refugees establish quality social connections and networks beyond their ethnic community that not only provide 
support in their current jobs but may help them identify future employment opportunities that otherwise would not be available through ethnic niche employment. When treated with respect and dignity, refugees' ethnic identities, cultural perspectives, and life/ work experiences are respected, which, in turn, will likely enhance the perceived high value of their uniqueness in the organization. This is especially the case where refugees are from collectivist cultures, where ethnic identity is particularly important (Newman et al., 2018). In addition, the propriety and sensitivity rules will help improve the mental health of refugees and will likely foster their identification with the host organization and sense of belongingness, resulting in workplace inclusion and long-term success in subjective resettlement.

\section{DISCUSSION}

Host country government agencies, ethnic communities and NGOs provide assistance with basic needs (food, shelter, and short-term healthcare provision) and some career services to refugees in the initial stage of the integration and resettlement process. In the process of seeking employment, however, refugees face language, sociocultural (e.g. lack of understanding of host country cultural norms and business practices), and institutional barriers (e.g. difficulty in obtaining work permit or visas). For the lucky few who are able to secure jobs, prior research shows that refugees are subject to workplace discrimination, stereotypes, skill degradation, and harassment, all of which prevent successful inclusion of refugees in the local work and lead to their perceptions of otherness, inequality and exclusion in the host country.

Despite the critical importance of employment in achieving successful refugee integration and resettlement, recent evidence shows that the workplace mistreatment and obstacles facing refugees make the integration and resettlement process difficult, if not impossible. There is little research on these issues in the management literature. This is a significant omission. To tackle 
the global refugee crisis, we argue that host country organizations need to be part of the solution and should play an active role in mitigating refugees' negative experiences and in fostering their perception of inclusion in the local workplace. Applying organizational justice theory (Colquitt, 2001; Colquitt et al., 2001) and Shore et al.'s (2011) inclusion framework, we demonstrate that all four types of organizational justice - procedural, informational, distributive, and interpersonal justice - are important in establishing organizational practices and policies that can serve as the foundation of refugee inclusion. Organizational justice theories hence serve as a framework for future practical action and research.

Organizational justice, by focusing on fairness in decision making, resource allocation processes, and interpersonal interactions, can effectively enhance refugees' perception of inclusion in the workplace, addressing refugees' needs for belongingness and uniqueness, two important dimensions of workplace inclusion in Shore et al.'s (2011) theorization. The focus of the refugee integration and resettlement process has been on fulfilling the need of belongingness through assimilation strategies (e.g. Strang \& Ager, 2010), we argue that justice-based practices and policies are critical in recognizing refugees' ethnic identities and their potential unique contributions to the host country organization. Due to the common stereotype that refugees “come here and they don't know anything" (Tomlinson, 2010, p. 284), many host country organizations fail to fully recognize the value of refugees' cultural perspectives, life/ work experiences and their potential contributions to the organization. Indeed, Ely and Thomas (2001) identified the integration-and-learning perspective as a condition under which cultural diversity enhanced work group functioning. According to the integration-and-learning perspective, the insights, skills and experiences of all employees are potentially valuable resources that the work group can use to rethink its primary tasks, redefine its market, products, as well as reformulate its 
strategies and practices that may further advance the organization's mission (Ely \& Thomas, 2001). Many refugees were well trained and held highly skilled jobs such as doctors, government officials and engineers in their home countries. From this perspective, we argue that justicebased practices and policies will help identify refugees' unique skills, experiences, as well as their unique insights, all of which could contribute to the collective learning and advancement of goals of the host country organization.

From this perspective, our analysis provides directions for future research on refugee inclusion in the workplace. The sense of belongingness is important, especially in the initial refugee integration and resettlement process. However, according to Shore et al.'s (2011) conceptualization, this is only one dimension of workplace inclusion. More studies are needed to address the issue of uniqueness in the refugee inclusion in the workplace. This is particularly important, because most recent refugees in Europe, for example, come from collectivist cultures where ethnic identities are considered important and much of the potential unique contribution of the refugees is poorly recognized and therefore is under-utilized. Future research should explore and identify other factors that may fulfill the need for uniqueness among refugees. For example, psychological safety theories (Brown \& Leigh, 1996) could be helpful in encouraging refugees to more freely share their perspectives with local employees. At the individual level, psychological safety refers to an employee's sense of being able to show and employ one's self without fearing negative consequences to self-image, status, or career. At the team level, team psychological safety is defined as a shared belief that a team is safe for taking interpersonal risks (Edmondson, 1999). At the organizational level, the organizational climate for psychological safety refers to formal and informal organizational practices and procedures guiding and supporting open and trustful interactions within the work environment (Baer \& Frese, 2003). Prior studies found that 
psychological safety at team and organizational level supported team-learning behavior (Edmondson, 1999) and enhanced firm performance and innovation (Baer \& Frese, 2003). We speculate that justice-based practices will likely support the creation of a sense of psychological safety among refugees, which in turn, will likely encourage them to share their feedback, input and perspectives with local coworkers and supervisors, promoting their perception of being valued, unique organizational members and creating opportunities for collective learning, creativity and innovation.

In addition, we encourage future research to explore and better understand refugees' motivation to integrate (the mirror image of inclusion from the workers' perspective) in the workplace. Prior research on qualified immigrants (Cerdin et al., 2014) found that the success of qualified immigrants largely depended on their motivation to integrate into the host country, which was explained by their motivation to migrate. For refugees, at least initially, their motivation to migrate is less relevant than the motivation to emigrate from their crisis-ridden home. Some may appreciate the opportunity to be received by the host country and the assistance provided by the local governments and NGOs, whereas others may consider the current host country merely as a stepping stone to another country which may provide better life or employment perspectives, or may consider the host country just a 'waiting room' until they can return back to their home country when the situation is improved. The variations in the motivation to integrate will likely influence the level of success in refugee inclusion in the workplace.

Our analysis and discussion of the current refugee crisis has significant multi-level implications for policy and practice. We have eschewed analysis of public policies in relation to acceptance and numbers of refugees into a country. Whilst crucial, these are high-level, 
contentious, political decisions and beyond our remit as business and management scholars. We note, however, that such decisions may have a significant impact on the international reputation and attractiveness of a country for international workers: the response to refugees and the way they are treated may well make other migrants more, or less, willing to consider that country as a potential base. So, governments need to carefully review the impact of their immigration policies and its wider effects not only on the country's ability to take advantage of international mobility in general but also on anti-refugee sentiment among host country nationals, which will impact inclusion. For example, Mulvey (2010) reported evidence of how the combination of the language framing of refugees (e.g. 'bogus' and 'clandestine') and social media (i.e. reports and news stories about refugees and asylum seekers) can contribute to a legitimacy deficiency of refugees, the institutionalization of hostility, as well as creating an inaccurate understanding of refugees among host country nationals. From this perspective, social programs are needed to combat anti-refugee sentiment and ensure that the public is informed, too, about refugees as a potential source of human capital benefiting the performance and competitiveness of local organizations and the national economy. As refugees are not a homogeneous group in terms of their human capital, host country governments may need to establish favorable policies (e.g. providing tax benefits) to encourage employment in knowledge-intensive industries as well as low-technology ones.

The process of assisting refugees to find work and to enhance inclusion would be improved where there are multilateral collaborations between governments, the International Organization for Migration (IOM), resettlement agencies, NGOs (e.g. Refugee Support Centers), private voluntary agencies and hiring organizations. For example, government and resettlement agencies are likely to be the first in contact with refugees and hence, in addition to existing 
security checks, they could provide preliminary assistance in evaluating and documenting refugees' qualifications, skill levels and work experiences, which may help hiring organizations reduce redundant resources and time in the hiring process. Such collective efforts can increase refugees' chances of being matched with the right job positions, ensuring the fair and optimal utilization of their skill sets. Relatedly, we suggest that humanitarianism approaches be considered in refugee settlement and inclusion. Clarke (2018) discusses how international coordination and generous humanitarian assistance packages lead to relatively peaceful conditions in the refugee camps in Turkey. Governments may also need to carefully evaluate whether their refugee policies and systems over-emphasize the need to assimilate over the more limited aim of inclusion. As our discussion and analysis show, assimilation policies may help create a sense of belonginess among refugees in the short-term, but fail to fulfill their need of uniqueness and hence jeopardize the opportunity for refugees to fully participate and contribute to the collective learning in the host country organization in the long run.

National and international NGOs have a key role to play. For example, in the EU, they can advocate making policies that require Europe to fulfil its human rights obligations towards refugees and grant them inclusion within its territory. So far, this advocacy work seeks to change exclusionary policies but its influence on the making of EU immigration policies remains very limited. For example, SOS Racism originated in France in the 1980s as an anti-racist NGO and now attempts to enlarge its network in many European countries. Another example is Humanity in Action, an NGO working on avoiding the emergence of state policies that are anti-refugee.

At a meso level, we discussed how justice-based business practices and policies can enhance the inclusion of refugees in the workplace. Our analysis provides important reasons and practical ways for business leaders and managers to recognize refugees' unique values and 
potential contributions to the collective learning, creativity and advancement of organizational performance. The recent report on refugee employees by Kallick and Roldan (2018) finds that refugees tend to stay longer with the same employer and have lower turnover rates than other hires, and that most hiring companies have learned and grown from the experience of including refugees, making them better employers in general, not just better employers of refugees. There is great potential for business to do more and we suggest that companies and business leaders take initiatives in hiring and including refugees in the local workforce. For example, Hamdi Ulukaya, the founder, Chairman and CEO of Chobani, founded Tent (www. tent.org), the online community which is dedicated to improving the lives and livelihoods of refugees by hiring refugees directly and integrating them into supply chains, designing services and products for the underserved refugee communities, and helping investment firms earn positive returns by investing in refugee-owned start-ups, small- or medium-sized companies. In doing so, host organizations provide partial solution and alleviate the current refugee crisis.

At the individual level, a greater awareness on the part of managers, supervisors and coworkers of the experiences and issues facing refugees, and of the skills and connections that they have, would ease their inclusion in the workplace (Gericke et al., 2018). As we discussed earlier, getting involved in the workforce and being accepted at work is crucial for the successful integration of refugees into their host country; the benefits and values that refugees can bring to the host country and the host country organization mean that investment in such awarenessbuilding will well pay off.

\section{CONCLUSION}

Given the global refugee crisis in various parts of the world, the acceptance of the important role of business and specifically of employment in refugee inclusion, and the limited 
understanding of this phenomenon in the management literature, it is important to consider potential future research. We need further research informing the international careers literature by directing attention from economic migrants to forced migrants such as refugees, and by explicating the different career obstacles they face and how host country organizations may provide support in removing these obstacles. We need to explore the role of host country governments, agencies and organizations in integrating refugees into the local workforce. The awareness of the host corporations and governmental institutions towards the refugee population, their different cultures, and specific needs is essential in facilitating a successful integration into local workforce. Governments, for instance, should avoid enforcing policies that isolate refugees due to unneeded employment/administrative restrictions. We suggest that organizational justice theory is of great relevance in understanding the situation and inclusion of refugees in the workplace. By applying organizational justice theory to structure our research, we make a contribution to the literature by explicating how different types of organizational justice may facilitate the inclusion of refugees in host country organizations and may provide them with opportunities to fully involve and contribute as valued citizens and organizational members in the host country. 


\section{REFERENCES}

20 Years of the UN Global Compact. (n.d.). Retrieved Feb 8, 2020 from https://www.unglobalcompact.org/take-action/20th-anniversary-campaign

Al Ariss, A., Koall, I., Özbilgin, M., \& Suutari, V. (2012). Careers of skilled migrants: towards a theoretical and methodological expansion. Journal of Management Development, 31, 92-101.

Alderfer, C. P., \& Smith, K. K. (1982). Studying intergroup relations embedded in organizations. Administrative Science Quarterly, 27, 35-65.

Baer, M., \& Frese, M. (2003). Innovation is not enough: climate for initiative and psychological safety, process innovations, and firm performance. Journal of Organizational Behavior, 24, 45-68.

Bies, R., \& Moag, J. (1986). Interactional justice: communication criteria of fairness, in R. Lewicki, B. Sheppard and M. Bazerman (Eds.) Research on Negotiations in Organizations, Vol. 1, pp. 43-55. Greenwich, CT: JAI Press.

Blader, S. L., \& Tyler, T. R. (2005). How can theories of organizational justice explain the effects of fairness, Are procedural justice and interactional justice conceptually distinct? In J. Greenberg and J. A. Colquitt (Eds.), Handbook of Organizational Justice (pp. 329354). Mahwah, NJ: Lawrence Erlbaum Associates.

Braithwaite, A., Salehyan, I., \& Savun, B. (2019). Refugees, foced migration, and conflict: introduction to the specia issue. Journal of Peach Research, 56, 5-11. 
Brandt, K. L. (2010).co Making immigrant integration work: a case study of refugee resettlement in Philadelphia, PA. (Unpublished master thesis). Massachusetts Institute of Technology, MA.

Brown, M. W., \& Leigh, T. W. (1996). A new look at psychological climate and its relationship to job involvement, effort and performance. Journal of Applied Psychology, 81, 358368.

Brücker, H., Hauptmann, A., \& Vallizadeh, E. (2015). Flüchtlinge und andere Migraten am deutschen Arbeitsmarkt: Der Stand im September 2015 (Refugees and other migrants in the German labour market: Levels in September 2015), Aktuelle Berichte, No. 14/2015, Institut für Arbeitsmarkt und Berufsforschung (IAB), Nürnberg.

Buckley, P. J., \& Casson, M. (1991). A long-run theory of the multinational enterprise. The Future of the Multinational Enterprise, 32-65.

Buengeler, C., \& Den Hartog, D. N. (2015). National diversity and team performance: The moderating role of interactional justice climate. International Journal of Human Resource Management, 26, 831-855.

Campion, E. D. (2018). The career adaptive refugee: exploring the structural and personal barriers to refugee resettlement. Journal of Vocational Behavior, 105, 6-16.

Carr, S. C., Inkson, K., \& Thorn, K. (2005). From global careers to talent flow: reinterpreting 'brain drain'. Journal of World Business, 40, 386-398.

Cerdin, J. -L., Abdeljalil-Diné, M., \& Brewster, C. (2014). Qualified immigrants' success: Exploring the motivation to migrate and to adjust. Journal of International Business Studies, 45, 151-168. 
Clarke, K. (2018). When do the dispossessed protest? Informal leadership and mobilization in Syrian refugee campus. Perspectives on Politics, 16, 617-633.

Clark, K., \& Drinkwater, S. (2000). Pushed out or pulled in? Self-employment among ethnic minorities in England and Wales. Labour Economics, 7, 603-628.

Collins, J. (2003). Cultural diversity and entrepreneurship: policy responses to immigrant entrepreneurs in Australia. Entrepreneurship \& Regional Development: In International Journal, 15, 137-149.

Colquitt, J. A. (2001). On dimensionality of organizational justice: a construct validation of a measure. Journal of Applied Psychology, 86, 386-400.

Colquitt, J. A., Conlon, D. E., Wesson, M. J., Porter, C. O. L. H., \& Ng, K. Y. (2001). Justice at the Millennium: a meta-analytic review of 25 years of organizational justice research. Journal of Applied Psychology, 86, 425-445.

Cortes, K. (2004). Are refugees different from economic immigrants? Some empirical evidence on the heterogeneity of immigrant groups in the United States. Review of Economics and Statistics, 86, 465-480.

Cox, T. H., \& Blake, S. (1991). Managing cultural diversity: implications for organizational competitiveness. Academy of Management Executive, 5, 45-56.

Cropanzano, R., Bowen, D., \& Gilliland, S. (2007). The Management of organizational justice. Academy of Management Perspectives, 21, 34-48.

Deutsch, M. (1975). Equity, equality, and need: what determines which value will be used as the basis for distributive justice?, Journal of Social Issues, 31, 137-149. 
Dietz, J., Joshi, C., Esses, V. M., Hamilton, L.K., \& Gabarrot, F. (2015). The skill paradox: explaining and reducing employment discrimination against skilled immigrants. International Journal of Human Resource Management, 26, 1318-1334.

Edmondson, A. (1999). Psychological safety and learning behavior in work teams. Administrative Science Quarterly, 44, 350-383.

Eggenhofer-Rehart, P. M., Latzke, M., Pernkopf, K., Zellhofer, D., Mayrhofer, W., \& Steyrer, J. (2018). Refugees' career capital welcome? Afghan and Syrian refugee job seekers in Austria. Journal of Vocational Behavior, 105, 31-45.

Ely, R. J., \& Thomas, D. A. (2001). Cultural diversity at work: the effects of diversity perspectives on work group processes and outcomes. Administrative Science Quarterly, 46, 229-273.

European Commission (2019). Support and Solidarity for Migration and Border Management under the EU budget. Retrieved January 15, 2020, from https://www.EC:/users/admin/downloads/2019-10-16-_EU_budget_on_migration.pdf.pdf

Evan, W., \& Fitzgerald, D. (2017). The economic and social outcomes of refugees in the United States: Evidence from the ACS. NBER Working Paper No. 23498.

Fairlie, R. W. (2008). Estimating the contribution of immigrant business owners to the US economy: SBA Office of Advocacy.

Farndale E., Biron, M., Briscoe, D. R., \& Raghuram, S. (2015). A global perspective on diversity and inclusion in work organisations. International Journal of Human Resource Management, 26, 677-687. 
Folger, R., \& Greenberg, J. (1985). Procedural justice: An interpretive analysis of personnel systems. In K. Rowland \& G. Ferris (Eds.), Research in Personnel and Human Resources Management, Vol. 3 (pp. 141-183). Greenwich, CT: JAI.

Gericke, D., Burmeister, A., Lowe, J., Deller, J., \& Pundt, L. (2018). How do refugees use their social capital for successful labor market integration? An exploratory analysis in Germany. Journal of Vocational Behavior, 105, 46-61.

Greenberg, J. (1993). The Social Side of Fairness: Interpersonal and Informational Classes of Organizational Justice, in R. Cropanzano (Ed.), Justice in the Workplace: Approaching Fairness in Human Resource Management, pp. 79-103. Hillsdale, NJ: Erlbaum.

Hakak, L. T., \& Al Ariss, A. (2013). Vulnerable work and international migrants: a relational human resource management perspective. International Journal of Human Resource Management, 24, 4116-4131.

Hassan, A., \& Hashim, J. (2011). Role of organizational justice in determining work outcomes of national and expatriate academic staff in Malaysia, International Journal of Commerce and Management, 21, 82-93.

Hicks-Clarke, D., \& Iles, P. (2000). Climate for diversity and its effects on career and organisational attitudes and perceptions, Personnel Review, 29, 324-345.

Hofstede, G. (1980). Culture's consequences: International differences in work-related values. Beverly Hills: Sage Publications.

Ilies, R., Wilson, K. S., \& Wagner, D. T. (2009). The spillover of daily job satisfaction onto employees' family lives: The facilitating role of work-family integration. Academy of Management Journal, 52, 87-102. 
IPSOS (2019). Global Attitudes towards Refugees, Retrieved January 15, 2020, from https://www.ipsos.com/sites/default/files/ct/news/documents/2019-06/World-RefugeeDay-2019-Ipsos.pdf

James, K. (1993). The social context of organizational justice: cultural, intergroup, and structural effects on justice behaviors and perceptions. In R. Cropanzano (Ed.), Justice in the workplace: Approaching fairness in human resource management (pp. 21-50). Hillsdale, NJ: Lawrence Erlbaum Associates.

Kallick, D. D., \& Roldan, C. (2018). Refugees as employees: good retention, strong recruitment, Fiscal Policy Insitute, Retrieved June 08, 2019, from https://www.tent.org/wpcontent/uploads/2018/05/TENT_FPI-Refugees-as-Employees-Report.pdf

Knappert, L., Kornau, A., \& Figengul, M. (2018). Refugees' exclusion at work and the intersection with gender: insights from the Turkish-Syrian border. Journal of Vocational Behavior, 105, 62-82.

Kossek, E. E., \& Zonia, S. C. (1993). Assessing diversity climate: a field study of reactions to employer efforts to promote diversity. Journal of Organizational Behavior, 14, 61-81.

Kroon, B., \& Paauwe, J. (2014). Structuration of precarious employment in economically constrained firms; the case of Dutch agriculture. Human Resource Management Journal, 24, 19-37.

Leventhal, G. S. (1980). What should be done with equity theory? New approaches to the study of fairness in social relationships. In K. J. Gergen, M. S. Greenberg, \& R. H. Willis (Eds.), Social Exchange: Advances in Theory and Research. New York: Plenum Press. 
Lundborg, P. (2013). Refugees' Employment Integration in Sweden: Cultural Distance and Labor Market Performance. Review of International Economics, 21, 219-232.

Marfleet, P., \& Blustein, D. L. (2011). 'Needed not wanted': An interdisciplinary examination of the work-related challenges faced by irregular migrants. Journal of Vocational Behavior, 78, 381-389.

Mennino, S. F., Rubin, B. A., \& Brayfield, A. A. (2005). Home-to-job and job-to-home spillover: The impact of company policies and workplace culture. The Sociological Quarterly, 46: 107-135.

Mor Barak, M. E. (2000). Beyond affirmative action: Toward a model of diversity and organizational inclusion. Administration in Social Work, 23, 47-68.

Mor Barak, M. E., \& Cherin, D. A. (1998). A tool to expand organizational understanding of workforce diversity: Exploring a measure of inclusion-exclusion. Administration in Social Work, 22, 47-64.

Mulvey, G. (2010). When policy creates politics: the problematizing of immigration and the consequences for refugee integration in the UK. Journal of Refugee Studies, 23, 437462.

Naccache, P., \& Al Ariss, A. (2017). The forced migration crisis and the role of European corporations: a point of view. European Management Review, 15, 589-596.

Nelson, J., Jenkins, B., \& Gilbert, R. (2015). Business and the sustainable development goals. Retrieved June 15, 2019, from http://www.igdleaders.org/wpcontent/uploads/BusinessandSDGs.pdf. 
New American Economy (2018). Opportunity Lost: The Cost of Rescinding the International Entrepreneur Rule. Retrieved 23/01/20 from https://research.newamericaneconomy.org/report/opportunity-lost-the-cost-of-rescinding$\underline{\text { the-international-entrepreneur-rule/ }}$

Newman, A., Nielsen, I., Smyth, R., Hirst, G., \& Kennedy, S. (2018). The effects of diversity climate on the work attitudes of refugee employees: The mediating role of psychological capital and moderating role of ethnic identity. Journal of Vocational Behavior, 105, $147-158$.

Nishii, L. H. (2013). The benefits of climate for inclusion for gender-diverse groups. Academy of Management Journal, 50, 1754-1774.

Orhan, O. (2014). The situation of Syrian refugees in the neighbouring countries: findings, conclusions and recommendations. Ankara: Center for Middle Eastern Strategic Studies (ORSAM). Retrieved January 24, 2019, from http://www.orsam.org.tr/en/enUploads/Article/ Files/201452_189ing.pdf.

Pajic, S., Ulceluse, M., Kismihók, G., \& Mol, S. T. (2018). Antecedents of job search selfefficacy of Syrian refugees in Greece and the Netherlands. Journal of Vocational Behavior, 105, 159-172.

Pateman, C. (1970). Participation and democratic theory. Cambridge: Cambridge University.

Pelled, L. H., Ledford, G. E., \& Mohrman, S. A. (2009). Demographic dissimilarity and workplace inclusion. Journal of Management Studies, 36, 1013-1031.

Phillimore, J., \& Goodson, L. (2006). Problem or opportunity? Asylum seekers, refugees, employment and social exclusion in deprived urban areas. Urban Studies, 43, 1715-1736. 
Porter, M. (1990). The competitive advantage of nations. Harvard Business Review (MarchApril): 73-91.

Reed, H., (2018). Forced migration and undocumented migration and development. United Nations Expert group meeting for the review and appraisal of the program of action of the international conference on population and development and its contribution to the follow-up and review of the 2030 agenda for sustainable development. Retrieved June 01, 2019, from https://www.un.org/en/development/desa/population/events/pdf/expert/28/EGM_Holly_R eed.pdf.

Robinson, G., \& Dechant, K. (1997). Building a business case for diversity. Academy of Management Executives, 11, 21-31.

Roberson, Q. M. (2006). Disentangling the meanings of diversity and inclusion in organizations. Group \& Organization Management, 31, 212-236.

Roberson, Q. M., \& Stevens, C. K. (2006). Making sense of diversity in the workplace: organizational justice and language abstraction in employees' accounts of diversityrelated incidents. Journal of Applied Psychology, 91, 379-391.

Rupp, D., Shapiro, D., Folger, R., Skarlicki, D., \& Shao, R. (2017). A critical analysis of the conceptualization and measurement of 'organizational justice': is it time for reassessment?' Academy of Management Annals, 11, 919-959.

Salehyan, I. (2019). Conclusion: what academia can contribute to refugee policy. Journal of Peace Research. 56, 146-151. 
Saxenian, A. L. (2005). Brian circulation and capitalist dynamics: Chinese chipmaking and the Silicon Valley-Hsinchu-Shanghai Triangle. In V. Nee \& R. Swedberg (Eds.), The economic sociology of capitalism (pp. 325- 351). Princeton NJ: Princeton University Press.

Schuetze, H. J., \& Antecol, H. (2006). Immigration, entrepreneurship and the venture start-up process. The Life cycle of entrepreneurial ventures, 107-135.

Shear, M. D. \& Kanno-Youngs, Z. (2019). Trump Slashes Refugee Cap to 18,000, Curtailing U.S.Role as Haven. The New York Times. Retrieved December 20, 2019, https://www.nytimes.com/2019/09/26/us/politics/trump-refugees.html.

Shore, L. M., Randel, A. E., Chung, B. G., Dean, M. A., Ehrhart, K. H., \& Singh, G. (2011). Inclusion and diversity in work groups: a review and model for future research. Journal of Management, 37, 1262-1289.

Strang, A., \& Ager, A. (2010). Refugee integration: emerging trends and remaining agendas. Journal of Refugee Studies, 23, 589-607.

Thomas, D. C., Lazarova, M. B., \& Inkson, K. (2005). Global careers: new phenomenon or new perspectives? Journal of World Business, 40, 340-347.

Tomlinson, F. (2010). Marking difference and negotiating belonging: Refugee women, volunteering and employment. Gender, Work and Organization, 17, 278-296.

Thibaut, J., \& Waker, L. (1975). Procedural justice: A psychological analysis. Hillsdale, NJ: Lawrence Erlbaum Associates.

Thomas, D. A., \& Ely, R. D. (1996). Making differences matter: A new paradigm for managing diversity. Harvard Business Review, 74, 79-90. 
Tyler, T. R., \& Blader, S. L. (2001). Identity and cooperative behavior in groups. Group Processes \& Intergroup Relations. 4, 207-226.

Tyler, T. R., \& Blader, S. L. (2003). The group engagement model: procedural justice, social identity, and cooperative behavior. Personality and Social Psychology Review, 7, 349361.

United Nations (2015). Global Compact A global compact for sustainable development-business and the SDGs: acting responsibly and finding opportunities. Retrieved January 28, 2019, from

https://www.unglobalcompact.org/docs/issues_doc/development/GCforSDbrochure.pdf.

United Nations, Department of Economic and Social Affairs, Population Division. (2017). International Migration Report 2017: Highlights (ST/ESA/SER.A/404). Retrieved January 25, 2019, from http://www.un.org/en/development/desa/population/migration/publications/migrationrepo rt/docs/MigrationReport2017_Highlights.pdf.

United Nations High Commission for Refugees (1951). United Nations Convention Relating to the Status of Refugees. Retrieved January 15, 2020, from https://www.nhcr.org/3b66c2aa10

United Nations High Commission for Refugees. (2016) Global Report. Retrieved January 25, 2019 from http://reporting.unhcr.org/sites/default/files/gr2016/pdf/Book_GR_2016_ENGLISH_com plete.pdf. 
United Nations High Commission for Refugees. (2018a). Global Appeal 2018-2019. Retrieved January 25, 2019 from https://www.unhcr.org/publications/fundraising/5a0c05027/unhcrglobal-appeal-2018-2019-full-report.html.

United Nations High Commission for Refugees. (2018b). UNHCR urges Hungary to withdraw draft law impacting refugees. Retrieved January 15, 2020, from https://www.unhcr.org/news/press/2018/5/5b0d71684/unhcr-urges-hungary-withdrawdraft-law-impacting-refugees.html

Wettstein, F., Guiliani, E., Santangelo, G., D., \& Stahl, G. K. (2019). International business and human rights: A research agenda. Journal of World Business, 54: 54-65.

\section{Author Biographies:}

Grace Chun Guo (chun-guog@sacredheart.edu) is associate dean of graduate programs and accreditation at the Jack Welch College of Business and Technology and associate professor of management at Sacred Heart University. Her research focuses on international migrant employees, international career mobility, and organizational justice She also studies entrepreneurship in emerging markets.

Akram Al Ariss (a.alariss@tbs-education.fr)

Chris Brewster (c.j.brewster@henley.ac.uk) 
